\title{
Biomechanics and physical examination of the posteromedial and posterolateral knee: state of the art
}

\author{
Steven T Swinford (D) , ${ }^{1}$ Robert LaPrade, ${ }^{2}$ Lars Engebretsen, ${ }^{3}$ Moises Cohen, ${ }^{4}$ \\ Marc Safran $^{5}$
}

Orthopaedic Surgery, Stanford University, Redwood City, California, USA

${ }^{2}$ Twin Cities Orthopedics, Edina, Minnesota, USA

${ }^{3}$ Orthopedic Department, Oslo universitetssykehus Ulleval, Oslo, Norway

${ }^{4}$ Orthopedic Department, Universidade Federal de São Paulo, São Paulo, São Paulo, Brazil

${ }^{5}$ Department of Orthopaedic Surgery, Stanford University Medical Center, Palo Alto, California, USA

\section{Correspondence to} Dr Steven T Swinford, Orthopaedic Surgery, Stanford University, Redwood City, CA 94063, USA;

swinford@stanford.edu

Received 29 January 2020

Revised 7 May 2020

Accepted 26 May 2020

Published Online First

14 July 2020
Check for updates

(C) International Society of Arthroscopy, Knee Surgery and Orthopaedic Sports Medicine 2020. No commercial re-use. See rights and permissions. Published by BMJ.

To cite: Swinford ST LaPrade R, Engebretsen L, et al. JISAKOS

2020:5:378-388.

\section{ABSTRACT}

The posteromedial and posterolateral corner structures contribute significantly to knee stability. The posterior oblique ligament is a primary restraint to internal rotation and a secondary restraint to valgus. The superficial fibres of the medial collateral ligament are the primary valgus restraint and also provide secondary internal and external rotation stability. The deep fibres of the medial collateral provide additional restraint to internal and external rotation as well as valgus. The posteromedial capsule provides a secondary restraint to valgus and posterior translation. The lateral (fibular) collateral ligament is the primary varus stabiliser. The popliteus tendon complex is a primary restraint to external rotation. The popliteofibular ligament is a secondary restraint to external rotation and varus. Many physical examination manoeuvres have been described to assess these structures. Manoeuvres assessing the posterolateral structures include the varus stress test, dial test, the posterolateral drawer, the external rotation recurvatum test, heel height test and the reverse pivot shift. Examination manoeuvres that assess the posteromedial structures include the valgus stress test, dial test, anterolateral drawer test and anteromedial drawer test. Proper application of physical examination manoeuvres in conjunction with other diagnostic modalities will allow providers to develop appropriate treatment plans.

\section{INTRODUCTION}

The last 20 years have demonstrated a growth in the knowledge of the importance of the posteromedial and posterolateral knee ligamentous and non-ligamentous structures and their functions. The posteromedial and posterolateral structures of the knee provide important contributions to overall knee stability. When left untreated, insufficiency of posteromedial or posterolateral structures can lead to patient morbidity through an increased risk of graft failure in cruciate ligament reconstructions or in the form of chronic rotatory instability. ${ }^{1-4}$ Clinicians therefore benefit from a sound understanding of the relevant biomechanics and the physical examination manoeuvres necessary to properly diagnose such injuries. From the early work of Hughston and Norwood in the 1970s to that of Gollehon, Grood and Noyes in the 1980s, orthopaedic surgeons have studied these structures to better elucidate their specific roles. ${ }^{5-7}$ These early studies have progressed to include more recent advanced research methodologies using better definition of quantitative anatomy, selective sectioning, load cells, and imaging techniques which have greatly advanced the understanding of the function and importance of these structures.

This state-of-the-art paper seeks to synthesise the current literature and provide the most up-todate international perspective of the biomechanics and physical examination of the posteromedial and posterolateral structures of the knee.

\section{TERMINOLOGY}

A number of recent review articles about the posteromedial and posterolateral corners of the knee demonstrate the continued interest of these structures. In 2017, Cinque and colleagues published a comprehensive review of the posteromedial corner describing the key anatomy, diagnostic tools and treatment options. ${ }^{8}$ They describe the posteromedial corner consisting of the deep and superficial medial collateral ligament (dMCL and sMCL), the posterior oblique ligament (POL), the oblique popliteal ligament and the posterior horn of the medial meniscus. Chahla and colleagues published a recent current concept review discussing the posterolateral corner focusing on the lateral collateral ligament (LCL), the posterior cruciate ligament (PCL), the popliteus tendon (PLT) and the popliteofibular ligament (PFL). ${ }^{9}$

Due to the complex kinematics of the knee, clear terminology must be used to describe its motion. Some of the confusion in the past has been differing terminology used for the same structures. For clarity in this paper and for consistency, the terms primary and secondary restraints will be used. As previously defined in the literature, primary restraints resist the majority of force in a given direction, while secondary restraints contribute to stability after the primary restraint has been removed and further excursion has occurred. ${ }^{10}$

\section{POSTEROMEDIAL CORNER ANATOMY}

Though a consensus has not been reached on what structures constitute the posteromedial corner, biomechanical evidence suggests that the sMCL, $\mathrm{dMCL}$ and POL are the most clinically relevant (figure 1). Several authors also recognise the semimembranosus tendon with its expansions, the posterior horn of the medial meniscus and the oblique popliteal ligament as important components of the posteromedial corner. ${ }^{81-13}$ Cadaveric evaluation of the semimembranosus tendon is limited by its dynamic nature. The medial meniscus similarly presents challenges to rigorous biomechanical evaluation due to its variable injury pattern and its propensity to undergo degenerative changes with age. These structures are omitted from this paper 


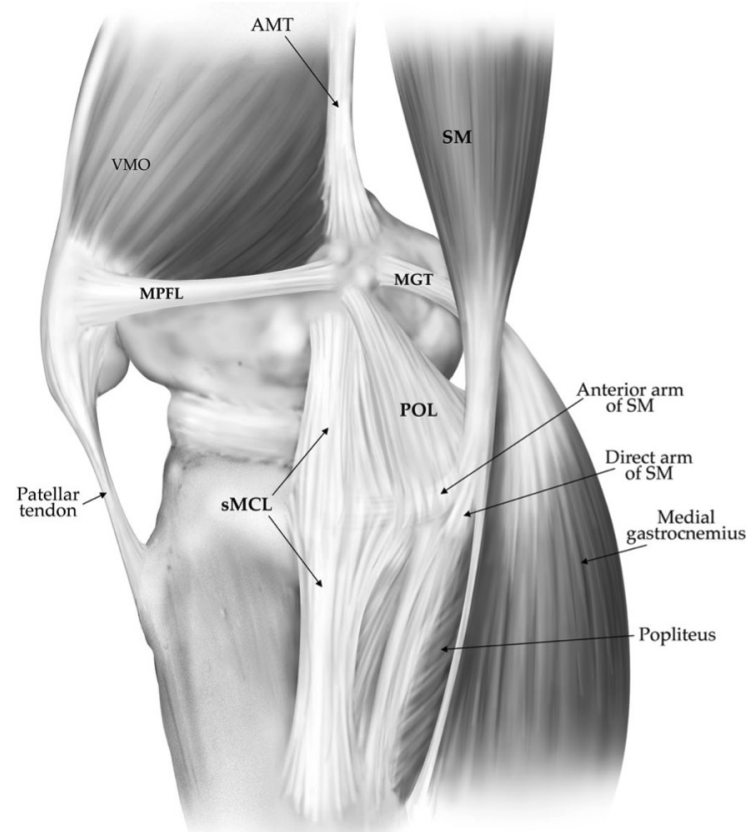

Figure 1 Illustration of the main medial knee structures (right knee). AMT, adductor magnus tendon; MGT, medial gastrocnemius tendon; MPFL, medial patellofemoral ligament; POL, posterior oblique ligament; SM, semimembranosus muscle; sMCL, superficial medial collateral ligament; VMO, vastus medialis obliquus muscle. Reprinted with permission. Adapted from LaPrade et al. ${ }^{61}$

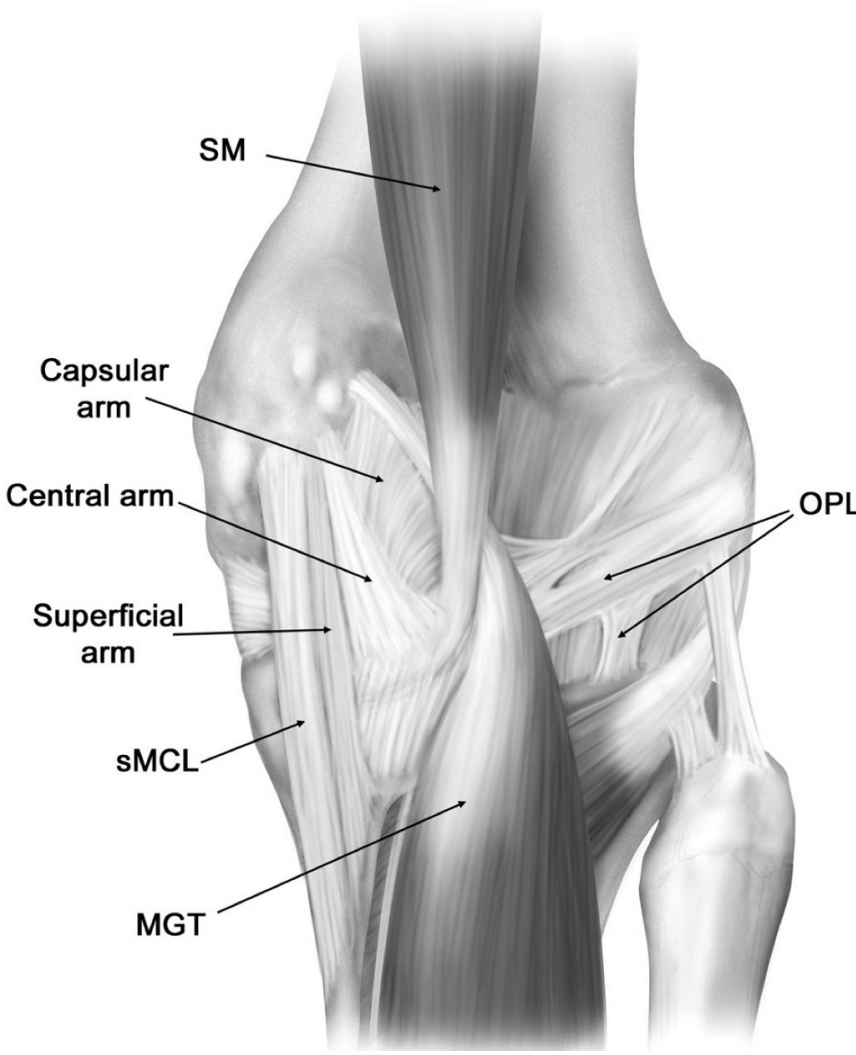

Figure 2 Illustration of the three arms of the posterior oblique ligament (posteromedial aspect, right knee). MGT, medial gastrocnemius tendon; OPL, oblique popliteal ligament; SM, semimembranosus muscle; SMCL, superficial medial collateral ligament. Reprinted with permission. LaPrade et al. ${ }^{61}$ due to a lack of biomechanical literature, but their importance should not be ignored.

\section{Medial collateral ligament}

The MCL is typically described as having deep and superficial components. The superficial component (sMCL) can be further subdivided into the proximal and distal superficial medial collateral ligament based on separate insertion sites. The dMCL is also subdivided into the meniscofemoral component and meniscotibial components, demarcated by the attachment to the medial meniscus. The overall function of the medial collateral ligament is stabilisation of the knee to resist valgus stress with additional contributions to external rotation and translation.

\section{Superficial medial collateral ligament}

As demonstrated in several biomechanical studies, the sMCL is the primary restraint to valgus stress at all angles of knee flexion and contributes restraint to both external and internal rotation. ${ }^{14-16}$ Griffith et al specifically identified the proximal sMCL to be the primary restraint to valgus at all angles of knee flexion. ${ }^{15}$ Primary external rotation restraint of the sMCL at $60^{\circ}$ and $90^{\circ}$ of knee flexion has been reported by Robinson et $a l^{16}$ while Griffith et $a l^{15}$ identified primary restraint to external rotation at $30^{\circ}$ of knee flexion and secondary external rotation restraint at $0^{\circ}, 20^{\circ}, 60^{\circ}$ and $90^{\circ}$ of knee flexion. The distal sMCL was described as a primary restraint to internal rotation at all angles of knee flexion by Griffith et $a l,{ }^{15}$ while Wijdicks et $a l^{17}$ recognised the sMCL as only a secondary stabiliser to internal rotation at $20^{\circ}$ of knee flexion. An intact cadaveric knee study using buckle transducers by Griffith et al ${ }^{14}$ documented lower sMCL stresses to internal rotation than to external rotation at all angles of knee flexion.

\section{Deep medial collateral ligament}

The dMCL contributes secondary restraint to valgus stress, internal rotation and external rotation of the knee. Multiple studies support dMCL valgus stress restraint. Griffith et $a l^{15}$ recognised the meniscofemoral and meniscotibial divisions both resist valgus at $60^{\circ}$ of knee flexion, Robinson et al ${ }^{16}$ reported secondary valgus restraint from $15^{\circ}$ to $90^{\circ}$ of knee flexion, and Wijdicks et $a l^{18}$ noted secondary restraint to valgus through the full range of knee flexion. There is mixed evidence with regard to the role of the $\mathrm{dMCL}$ in restraining internal rotation. Griffith et $a l^{15}$ reported the meniscofemoral component of the $\mathrm{dMCL}$ was a primary restraint to internal rotation at $20^{\circ}, 60^{\circ}$ and $90^{\circ}$ of knee flexion and a secondary restraint to internal rotation at $0^{\circ}$ and $30^{\circ}$ of knee flexion. The meniscotibial component was reported to be a secondary restraint to internal rotation at $0^{\circ}$, $30^{\circ}$ and $90^{\circ}$ of knee flexion. In contrast, Robinson et al ${ }^{16}$ were unable to demonstrate a role for the $\mathrm{dMCL}$ in resisting internal rotation. LaPrade and Wijdicks ${ }^{19}$ described the meniscofemoral division as a secondary restraint to both internal rotation and external rotation. Wijdicks and colleagues ${ }^{18}$ found the $\mathrm{dMCL}$ to be a secondary restraint to external rotation between $30^{\circ}$ and $90^{\circ}$ of knee flexion.

\section{Posterior oblique ligament}

The POL functions as a primary restraint to internal rotation of the tibia as well as a secondary restraint to valgus and external rotation. ${ }^{11}$ Multiple studies have recognised the POL as a primary restraint to internal rotation at all angles of knee flexion, with LaPrade and Wijdicks ${ }^{19}$ and Griffith et $a l^{15}$ noting more significant contribution with the knee in extension. ${ }^{14} 1519$ 
Further, Wijdicks et $a l^{18}$ described a reciprocal function between the POL and the sMCL in resisting internal rotation. The POL provides more internal rotation restraint in extension while the sMCL contributes more restraint in higher degrees of knee flexion. The POL has also been identified as a secondary restraint to external rotation at $30^{\circ}$ of knee flexion ${ }^{14}$ as well as at $60^{\circ}$ on knee flexion. ${ }^{17}$ Last, the POL is a secondary restraint to valgus at $0^{\circ}, 20^{\circ}$ and $30^{\circ}$ of knee flexion ${ }^{14}{ }^{17}$ (figure 2).

\section{Posteromedial capsule}

The posteromedial capsule (PMC) serves as a secondary restraint to valgus when the knee is extended. Only two studies were identified that specifically evaluated the biomechanical function of the PMC. Grood et $a l^{6}$ reported that the PMC contributed to $17.5 \%$ of valgus restraint at $5^{\circ}$ of knee flexion which diminished to $3.6 \%$ at $25^{\circ}$ of knee flexion. Robinson $e$ a $l^{16}$ also found that the PMC was a secondary restraint to valgus in knee extension.

\section{POSTEROLATERAL CORNER ANATOMY}

The main static stabilisers of the posterolateral corner are traditionally described as consisting of the lateral (fibular) collateral ligament (LCL), the popliteofibular ligament (PFL) and the popliteus tendon (PLT). Literature supports the clinical relevance of the LCL, the PLT and the PFL (figure 3).

\section{Lateral collateral ligament}

The LCL provides primary varus stability. ${ }^{6}$ LaPrade et al ${ }^{20}$ performed a biomechanical sectioning study evaluating the varus restraint provided by the posterolateral corner structures at $20^{\circ}$ of knee flexion. Using stress radiographs, they demonstrated that incremental lateral joint space widening occurred after sectioning of the LCL and PLT. Isolated LCL injury increased lateral opening asymmetry by $2.7 \mathrm{~mm}$ to a clinician-applied static varus moment. This increased by $4.0 \mathrm{~mm}$ with additional injury to the PLT and PFL. Additional resection of the anterior cruciate ligament (ACL) led to an increased lateral joint space of $5.3 \mathrm{~mm}$. Application of a mechanical varus moment by a load cell also demonstrated similar findings. They concluded that the use of varus stress radiography may provide an objective tool to diagnose lateral knee injury.

\section{Popliteus tendon complex}

The PLT is a primary restraint to external rotation of the tibia and secondary restraint to varus and posterior translation. ${ }^{21} 22$ Covey $^{21}$ reviewed several biomechanical studies focused on the posterolateral corner. They cite that the PLT provides primary restraint to external rotation of the tibia with the knee in $20^{\circ}$ to $130^{\circ}$ of knee flexion. In addition, they note restraint to varus between the knee flexion angles of $0^{\circ}$ and $90^{\circ}$. Further, Veltri et $a l^{22}$ reported that the PLT provided restraint to posterior translation, varus rotation and external rotation. And finally, Höher et $a l^{23}$ reported that the PLT and the LCL serve as secondary restraints to posterior translation in a PCL-deficient knee. A more recent study by LaPrade et $a l^{24}$ evaluated the static contribution of the popliteus tendon using cadaveric sectioning followed by anatomical reconstruction. They identified increased external rotation of the tibia with PLT sectioning at $30^{\circ}, 60^{\circ}$ and $90^{\circ}$ of knee flexion. This was restored to baseline with their anatomical reconstruction technique. They also noted a small but significant increase in internal rotation and varus angulation after sectioning that did not resolve with PLT reconstruction. No differences were seen in posterior translation. Based on these findings, the PLT plays a primary role in external rotation restraint (figure 3).

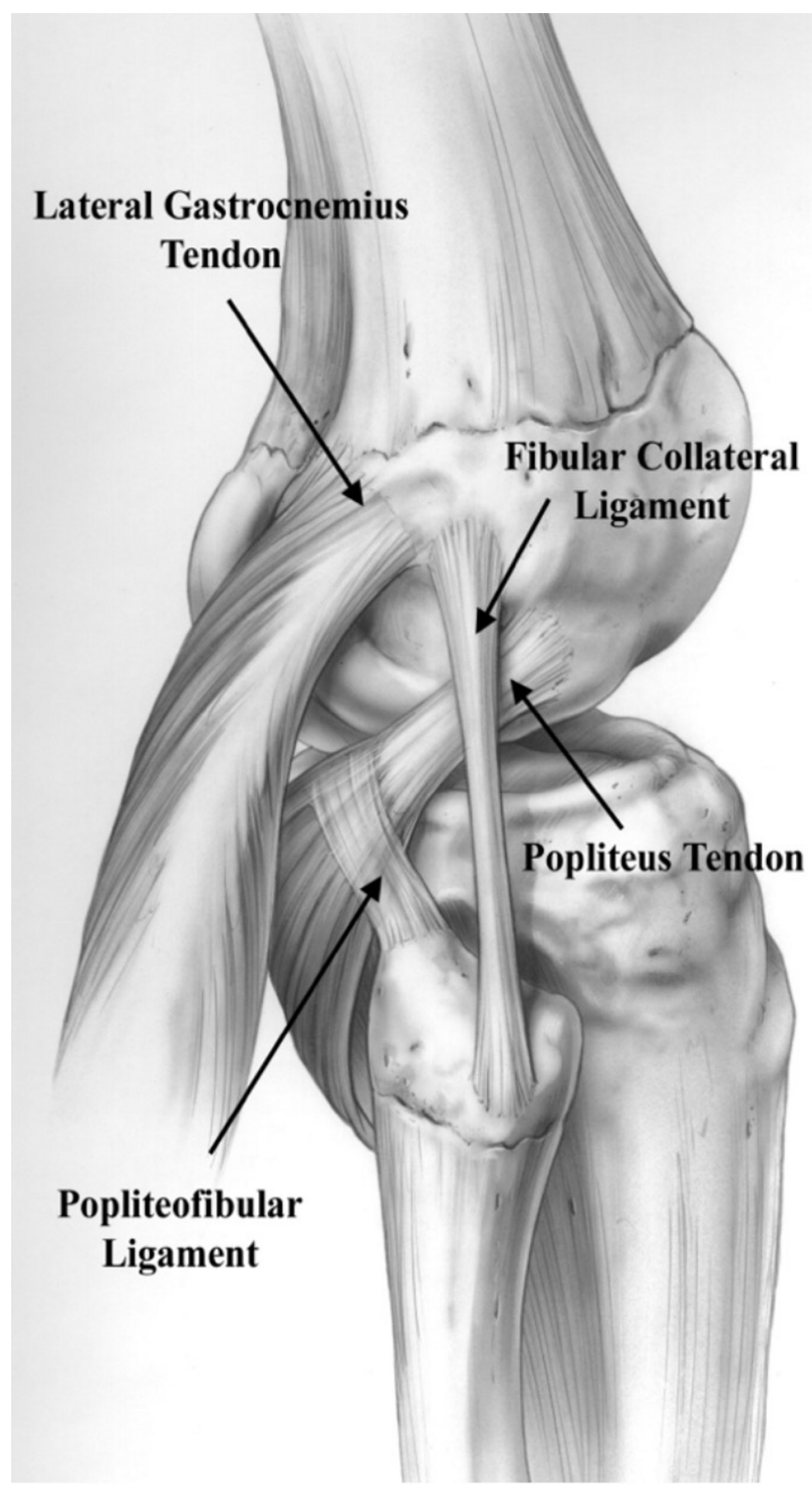

Figure 3 Posterolateral structures - the lateral collateral ligament (fibular collateral), the popliteus tendon and the popliteofibular ligament are the most biomechanically significant structures of the posterolateral corner. Reprinted with permission of SAGE Publications. Adapted from LaPrade et al. ${ }^{62}$

\section{Popliteofibular ligament}

The PFL functions as a primary restraint to external rotation with a mild secondary contribution to varus stability and internal rotation restraint. Maynard et $a l^{25}$ assessed the role of the PFL in a cadaveric varus load to failure study. After isolating the LCL, PFL and PLT, a pure varus moment was applied to cadaveric knees. They reported that the LCL fails first, the PFL second and the PLT third, highlighting the secondary role of the PFL in varus restraint. Veltri et $a l^{26}$ performed a cadaveric study to examine the static contributions of the popliteus complex to knee stability by selectively cutting the LCL, the PFL and the PLT attachment to the tibia. They found that the PFL and the PLT were important in resisting posterior translation, varus rotation and external rotation. McCarthy et $a l^{27}$ evaluated the role of PFL reconstruction in a cadaveric posterolateral corner 


\begin{tabular}{|c|c|c|c|}
\hline \multicolumn{4}{|c|}{ Essential features of posteromedial and posterolateral structures of the knee } \\
\hline Structure & Primary role & Secondary role & $\begin{array}{l}\text { Physical examination } \\
\text { manoeuvres }\end{array}$ \\
\hline sMCL & $\begin{array}{l}\text { Valgus at all angles } \\
\text { of knee flexion }\end{array}$ & External rotation & $\begin{array}{l}\text { Valgus stress test } \\
\text { Internal rotation } \\
\text { Posterior drawer } \\
\text { Anterolateral drawer } \\
\text { Anteromedial rotatory } \\
\text { instability }\end{array}$ \\
\hline $\mathrm{dMCL}$ & & $\begin{array}{l}\text { Valgus, external } \\
\text { rotation, internal } \\
\text { rotation }\end{array}$ & Valgus stress test \\
\hline POL & $\begin{array}{l}\text { Internal rotation } \\
\text { (especially in full } \\
\text { extension) and } \\
\text { external rotation }\end{array}$ & Valgus & $\begin{array}{l}\text { Anterolateral drawer } \\
\text { Anteromedial rotatory } \\
\text { instability } \\
\text { Anteromedial drawer }\end{array}$ \\
\hline PMC & & $\begin{array}{l}\text { Posterior translation, } \\
\text { internal rotation, } \\
\text { valgus }\end{array}$ & $\begin{array}{l}\text { Anteromedial drawer } \\
\text { Anteromedial rotatory } \\
\text { instability }\end{array}$ \\
\hline LCL & Varus & & $\begin{array}{l}\text { Varus stress } \\
\text { Figure of four } \\
\text { Heel height test }\end{array}$ \\
\hline PLT & External rotation & $\begin{array}{l}\text { Posterior translation, } \\
\text { varus }\end{array}$ & $\begin{array}{l}\text { Dial test } \\
- \text { Reverse pivot shift }\end{array}$ \\
\hline PFL & & $\begin{array}{l}\text { Posterior translation, } \\
\text { varus, internal } \\
\text { rotation, external } \\
\text { rotation }\end{array}$ & $\begin{array}{l}\text { Dial test } \\
\text { Reverse pivot shift }\end{array}$ \\
\hline $\mathrm{PCL}$ & $\begin{array}{l}\text { Posterior } \\
\text { translation, external } \\
\text { rotation }\end{array}$ & $\begin{array}{l}\text { Varus, valgus in } \\
\text { extension }\end{array}$ & $\begin{array}{l}\text { Posterior drawer } \\
\text { Dial test-at } 90^{\circ} \\
\text { Reverse pivot shift } \\
\text { Varus—in extension } \\
\text { Posterior sag } \\
\text { Quadriceps active }\end{array}$ \\
\hline
\end{tabular}

$\mathrm{dMCL}$, deep medial collateral ligament; $\mathrm{LCL}$, lateral collateral ligament; $\mathrm{PCL}$, posterior cruciate ligament; PFL, popliteofibular ligament; PLT, popliteus tendon; PMC, posteromedial capsule; POL, posterior oblique ligament; SMCL, superficial medial collateral ligament.

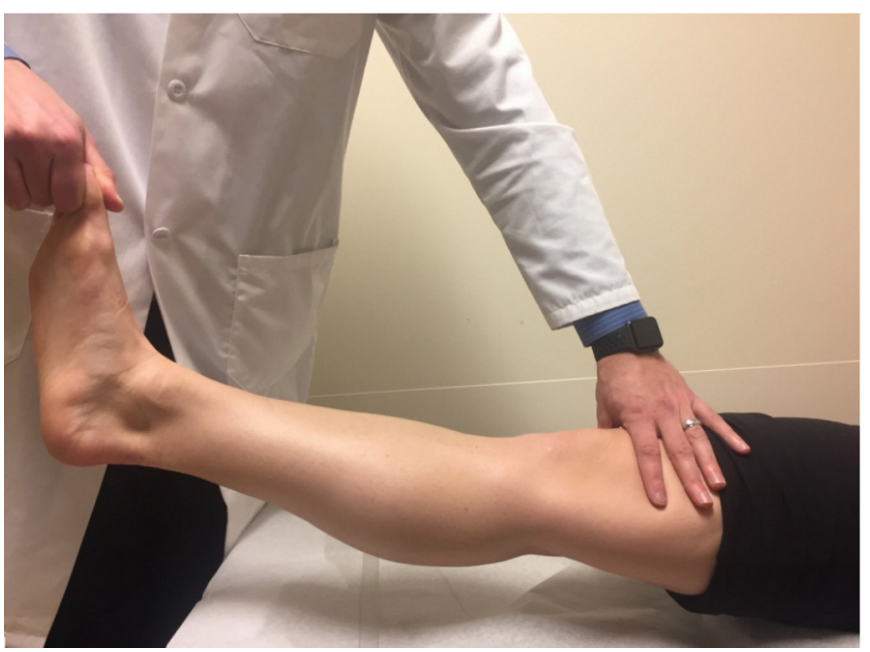

Figure 4 External rotation recurvatum test-the patient is positioned supine. The examiner then suspends the limb by the great toe and holds the thigh down toward the examining table while assessing for hyperextension, varus angulation and external rotation of the knee. The uninjured knee serves as a comparison. reconstruction model. They compared motion of cadaveric knees while intact, after sectioning of the LCL, PFL and PLT, and after reconstruction of the LCL and PLT with or without PFL reconstruction. Reconstructions that excluded the PFL reconstruction left residual varus gapping at $0^{\circ}, 20^{\circ}$ and $60^{\circ}$ of knee flexion as well as increased internal rotation at $60^{\circ}$ and $90^{\circ}$ of knee flexion. Reconstructions that included the PFL restored motion statistically similar to the intact state. These data suggest the PFL provides a small but significant role in restricting abnormal internal rotation and varus motion (figure 3).

\section{Posterior cruciate ligament}

Several biomechanical studies have been performed to assess the role of the PCL. In summary, the PCL is a primary restraint to posterior tibial translation and also contributes secondary restraint to varus, valgus and external rotation. ${ }^{28-31}$ Several cadaveric studies have identified primary restraint to posterior tibial translation through isolated PCL sectioning. ${ }^{128-31}$ Others have also noted the secondary restraint to varus and external rotation. ${ }^{6}{ }^{30}$ Combined injury has also been assessed. Sekiya and colleagues noted that a posteriorly directed stress in $90^{\circ}$ of knee flexion produced $<10 \mathrm{~mm}$ of posterior translation after isolated PCL sectioning but $19.5 \mathrm{~mm}$ of posterior displacement with concomitant sectioning of the remaining posterolateral corner. ${ }^{1}$ The same study also noted increasing external tibial rotation modelling the dial test when combining posterolateral corner injury with PCL injury at both $30^{\circ}$ and $90^{\circ}$ of knee flexion. In an assessment of medial knee instability, LaPrade et $a b^{32}$ noted that combined sMCL and ACL injury produced larger valgus instability than combined SMCL and PCL injury at $20^{\circ}$ of knee flexion, but that the opposite held true when the knee was in extension. This implies that the PCL is a more significant secondary restraint to valgus in extension while the ACL is a more significant secondary valgus restraint at $20^{\circ}$ of knee flexion.

\section{PHYSICAL EXAMINATION}

\section{General considerations}

Physical examination is an integral tool in the appropriate diagnosis of the patient. It is generally agreed to be the "cornerstone of successful diagnosis and subsequent treatment of complex knee injuries". ${ }^{33}$

Physicians must account for potential guarding in the injured patient, especially during the acute phase. Patient muscle tone can limit the sensitivity of physical examination manoeuvres. ${ }^{18}$ Some authors advocate for examination under anaesthesia or use of non-invasive testing such as MRI. While MRI is unquestionably a valuable tool, it is not perfectly accurate. Thus, it should be used in conjunction with patient history and physical examination. MRI has been shown to be useful in the acutely injured patient for identifying posterolateral corner injuries but less reliable in the chronic setting. ${ }^{34}$ Patient factors such as ligamentous laxity and body habitus can influence physical examination. Physicians should therefore compare physical examination findings of the injured knee to the contralateral uninjured side whenever possible.

Physical examination is also dependent on the proficiency of the physician. A study comparing results of a mechanically applied load to that of a skilled practitioner demonstrated excellent correlation of radiographically measured findings. ${ }^{32}$ In contrast, Branch and colleagues compared the accuracy of a robotic testing device to the hands of an orthopaedic practitioner and found that the robotic testing outperformed the human. ${ }^{35}$ 


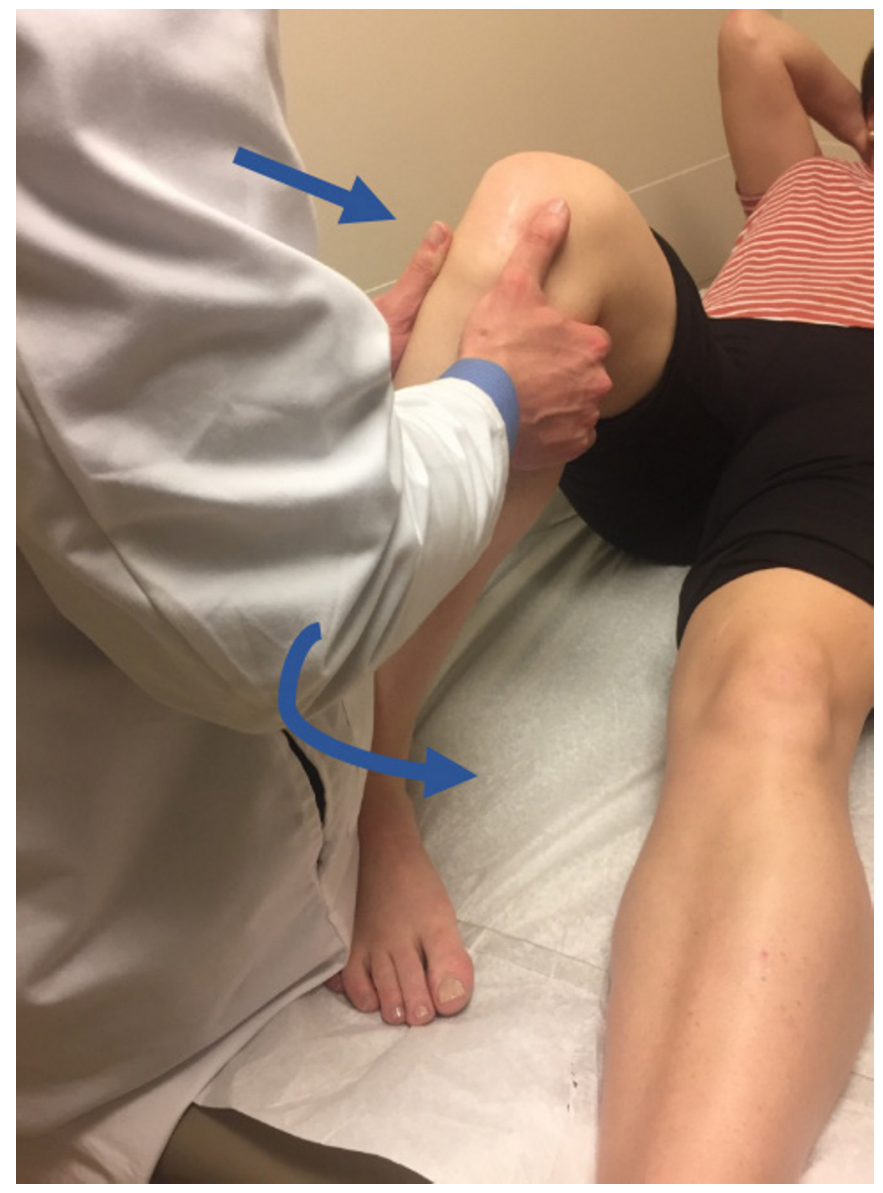

Figure 5 Internal rotation posterior drawer-the patient is positioned supine with the knee flexed to $90^{\circ}$. The examiner applies an internal rotation load to the tibia and supports the foot. A posteriorly directed force is then applied to the tibia while the examiner palpates for posterior translation of the medial tibial plateau relative to the medial femoral condyle.

Several instrumented systems are available to assist in obtaining objective laxity measurements, although these are not widely used. The Rottometer, the ROTAM (Genourob, Laval, France), the Rotameter and the Branch device are examples of external devices designed to assist in measuring knee rotation. The Rottometer holds the knee in a fixed degree of flexion and allows the examiner to apply a defined rotational moment. Almquist et $a l^{36}$ assessed the reliability in live subjects of the Rottometer using Roentgen Stereometric Analysis. They found an overestimation of tibial rotation by approximately $100 \%$ attributable to soft-tissue motion and compensatory movement in adjacent joints. Good correlation was observed between the two measurement methods with an $\mathrm{r}^{2}$ of 0.87 . A later study by Almquist and colleagues demonstrated good to excellent intra-rater correlation coefficient when applying moments of 6 or $9 \mathrm{Nm}$. Worse correlation was observed when using $3 \mathrm{Nm}$ moments. ${ }^{37}$ The ROTAM applies a motorised tibial rotational moment with the thigh and ankle held in fixed positions and has been used to mimic the dial test. ${ }^{38}$ The Rotameter allows the examiner to apply a precise rotational moment to a limb while the ankle is stabilised in a customised boot. Cadaveric comparison of the Rotameter relative to a navigation system showed overestimation of rotation from $5^{\circ}$ to $25^{\circ}$ with high correlation coefficients ranging from 0.90 to 0.95 for external rotation and $0.87-0.93$ for internal rotation. ${ }^{39}$ Better correlation was observed at higher magnitudes of applied moments. In live human subjects, the Rotameter showed similarly high levels of intra-observer and inter-tester reliability. ${ }^{40}$ The Branch device is another robotic apparatus which demonstrated excellent intraclass correlation coefficients of 0.97 for tibial rotation in patients lying supine with knees flexed to $25^{\circ} .{ }^{41}$ The Vermont knee laxity device is a system developed to assess anterior-posterior motion of a knee in non-weightbearing and simulated weightbearing conditions. The reliability of the Vermont knee laxity device was compared with that of the KT-1000 knee arthrometer (Medmetric, San Diego, CA) in a study by Un and colleagues. ${ }^{42}$ They identified significant differences in inter-observer reliability but no differences in intra-rater reliability.

While the remainder of this section will focus on specific examination manoeuvres, the physical examination should begin with inspection and palpation as these basic components can provide valuable information to the practitioner and calibrate level of suspicion for specific injuries appropriately (table 1).

\section{Posterolateral corner examination manoeuvres} Varus stress test

The varus stress test is a crucial component to accurate physical diagnosis of posterolateral corner injury. Varus testing with the knee in full extension and at $30^{\circ}$ of flexion has been documented by several studies to aid in diagnosis of isolated LCL injury versus

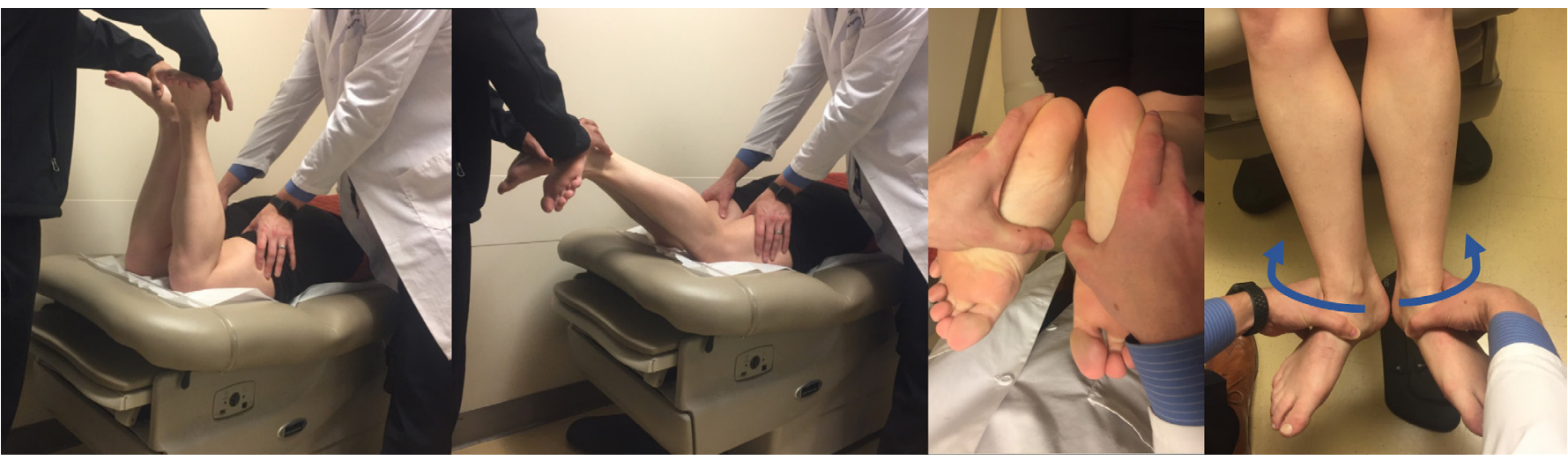

Figure 6 Dial test - the dial test may be performed with the patient prone or supine. An external rotation stress is applied by the examiner through the patient's feet with the knees flexed to both $90^{\circ}$ and $30^{\circ}$. The examiner assesses for relative increase in external rotation of the injured limb. In these images, the patient's thighs are adducted and stabilised by an assistant. 


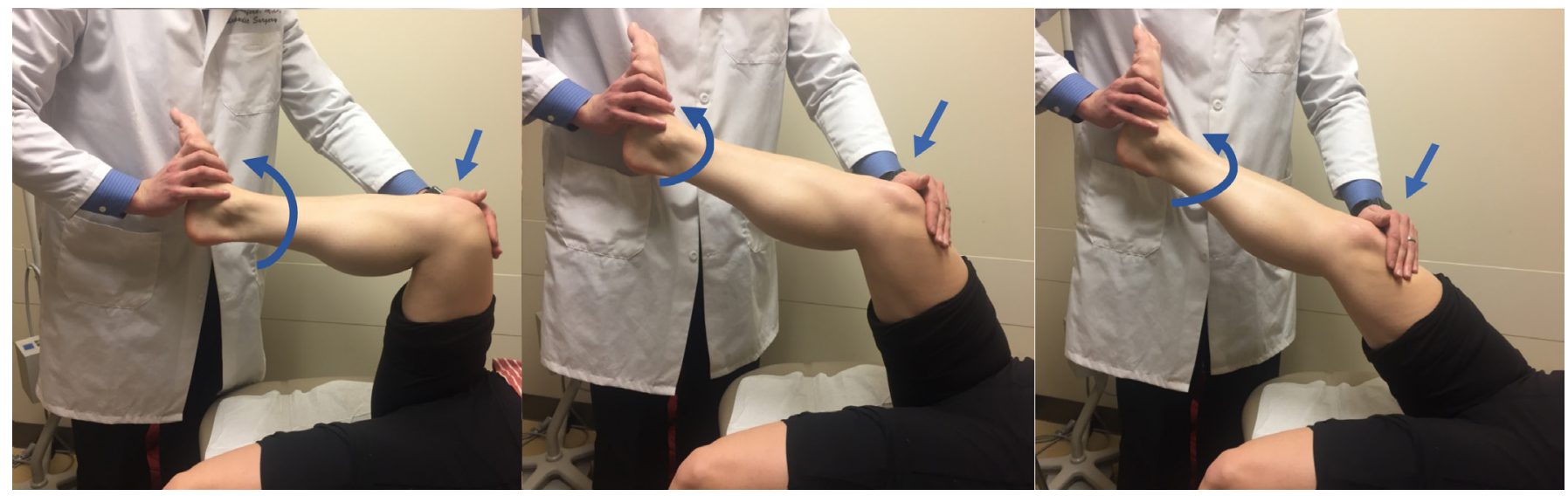

Figure 7 Reverse pivot shift test — the patient is positioned supine with the knee flexed to $90^{\circ}$. External rotation and valgus loads are applied by the examiner and the knee is gradually extended. A positive test is indicated by the palpable reduction of the posteriorly subluxated lateral tibial condyle.

additional PCL injury. Concomitant cruciate injury is evidenced by increased varus instability in extension. ${ }^{20} 30$

\section{External rotation recurvatum test}

The external rotation recurvatum test is performed by suspending both legs of the patient in supine position by the great toes and observing the tibial relationship to the femur

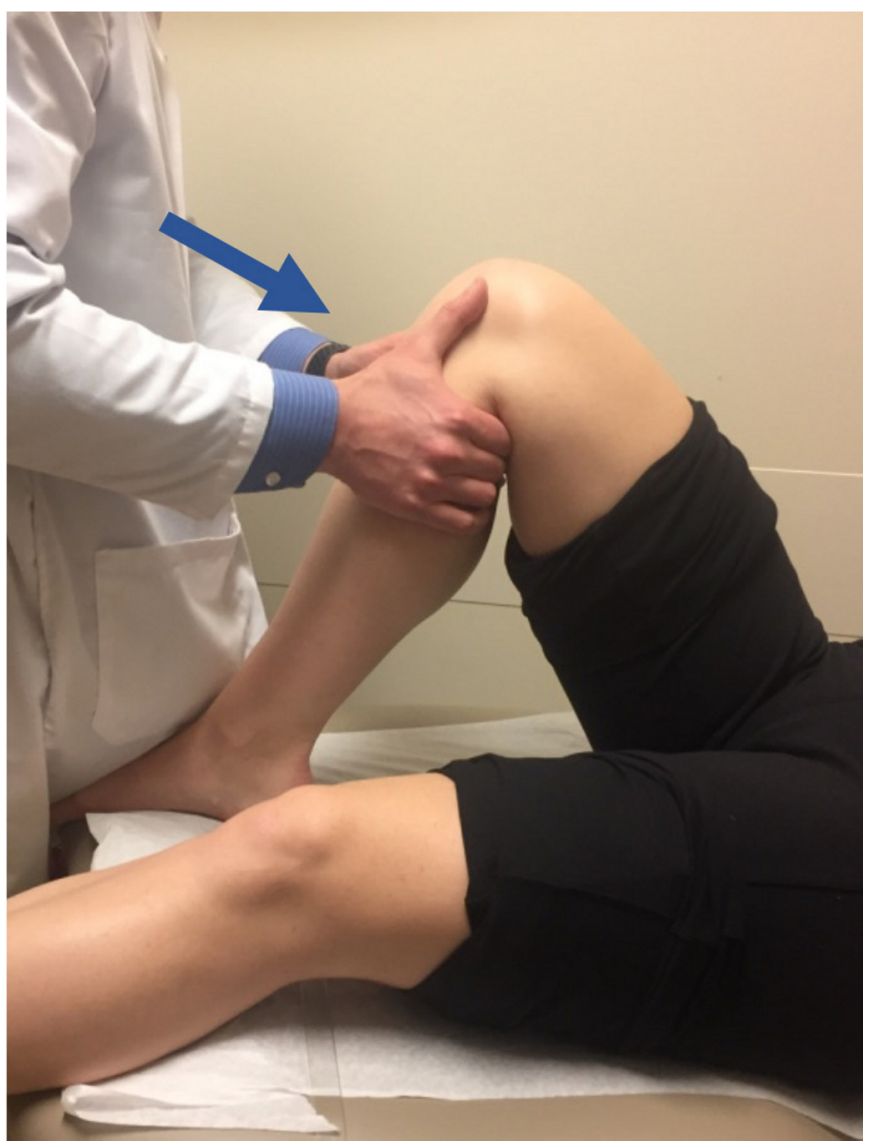

Figure 8 Posterolateral drawer test-the patient is positioned supine with the knee flexed to $90^{\circ}$. The examiner then places an external rotation and posteriorly directed force on the proximal tibia and stabilises the foot. The examiner assesses for posterolateral rotation of the tibia and palpates for step-off of the lateral tibial plateau relative to the lateral femoral condyle. bilaterally. Historically, a positive test was described as relative hyperextension of the knee with relative external rotation of the tibial tubercle and varus deformity of the knee. ${ }^{5}$ The external rotation recurvatum test was considered positive when the ACL, PCL and posterolateral corner (PLC) are injured. ${ }^{43}$ Older studies evaluating the accuracy of this test had reported a sensitivity between $73 \%$ and $80 \%$ among patients with documented posterolateral corner injury. ${ }^{43-45}$ More recently, a rigorous evaluation of the external rotation recurvatum test was performed by LaPrade et al using both clinical examination and radiographic findings. ${ }^{46}$ Their group identified only $7.5 \%$ sensitivity of the test among 134 patients confirmed intraoperatively to have PLC injury. Radiographs also demonstrated anterior translation of the tibia relative to the femur in all patients, rather than the anticipated and previously described posterior subluxation. Last, they identified combined ACL and PLC injury in all patients with a positive external rotation recurvatum test. In light of this more recent research, a positive external rotation recurvatum test is defined as increased recurvatum, varus widening and anterior translation of the tibia relative to the femur. It is indicative of a combined PLC and ACL injury. This test does not provide insight into the specific PLC structures that are incompetent, though a significant injury to multiple posterolateral structures is inferred (figure 4).

\section{Heel height test}

The heel height test is a variant of the external rotation recurvatum test used to differentiate between isolated ACL tears and combined ACL and LCL tears. With the patient in a supine position, the examiner lifts the great toe while stabilising the distal thigh to prevent knee elevation and thigh rotation. An assistant measures the distance between the heel and the examination table. This measurement is compared with the contralateral side. Cinque et al reported a $2.5 \mathrm{~cm}$ difference indicated combined injury with $74 \%$ sensitivity, $92 \%$ specificity, $86 \%$ positive predictive value and $86 \%$ negative predictive value. ${ }^{47}$ The heel height test compared favourably to MRI which had only $48 \%$ sensitivity and $88 \%$ specificity across the same patient population.

\section{Internal rotation posterior drawer manoeuvre}

The internal rotation variant of the posterior drawer manoeuvre distinguishes between isolated PCL injury and combined injury of the PCL with sMCL injury. Hughston and Norwood described positioning the tibia of the supine patient, with the knee flexed 


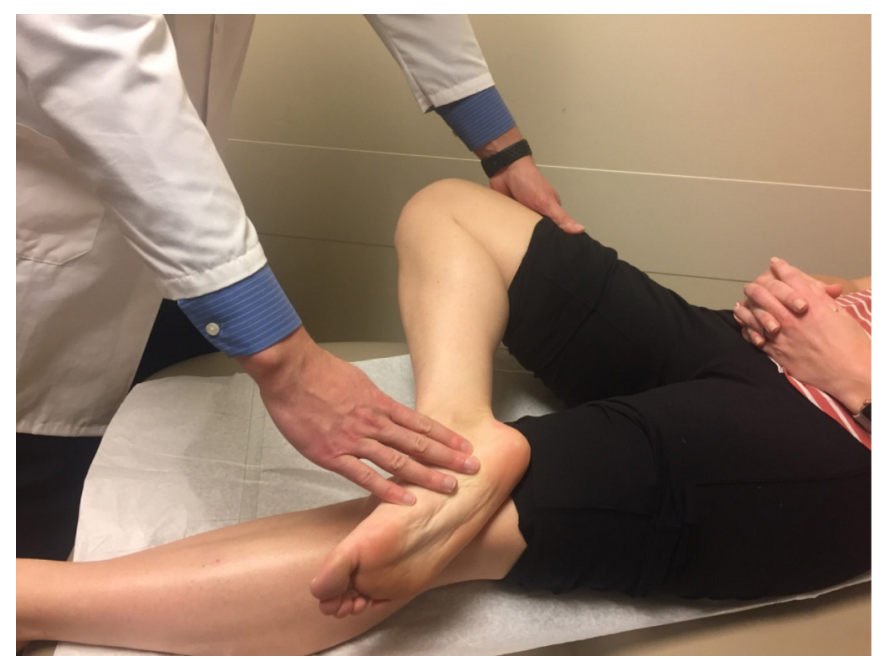

Figure 9 Figure-of-four manoeuvre - with the patient supine, the ankle of the injured extremity is rested on the anterior surface of the contralateral thigh. The examiner then palpates for a taut lateral collateral ligament between the lateral femoral epicondyle and the mid-fibular head.

to $90^{\circ}$, in internal rotation. ${ }^{5}$ A posteriorly directed force is then applied to the tibia. The degree of posterior displacement with internal rotation is compared with the displacement observed

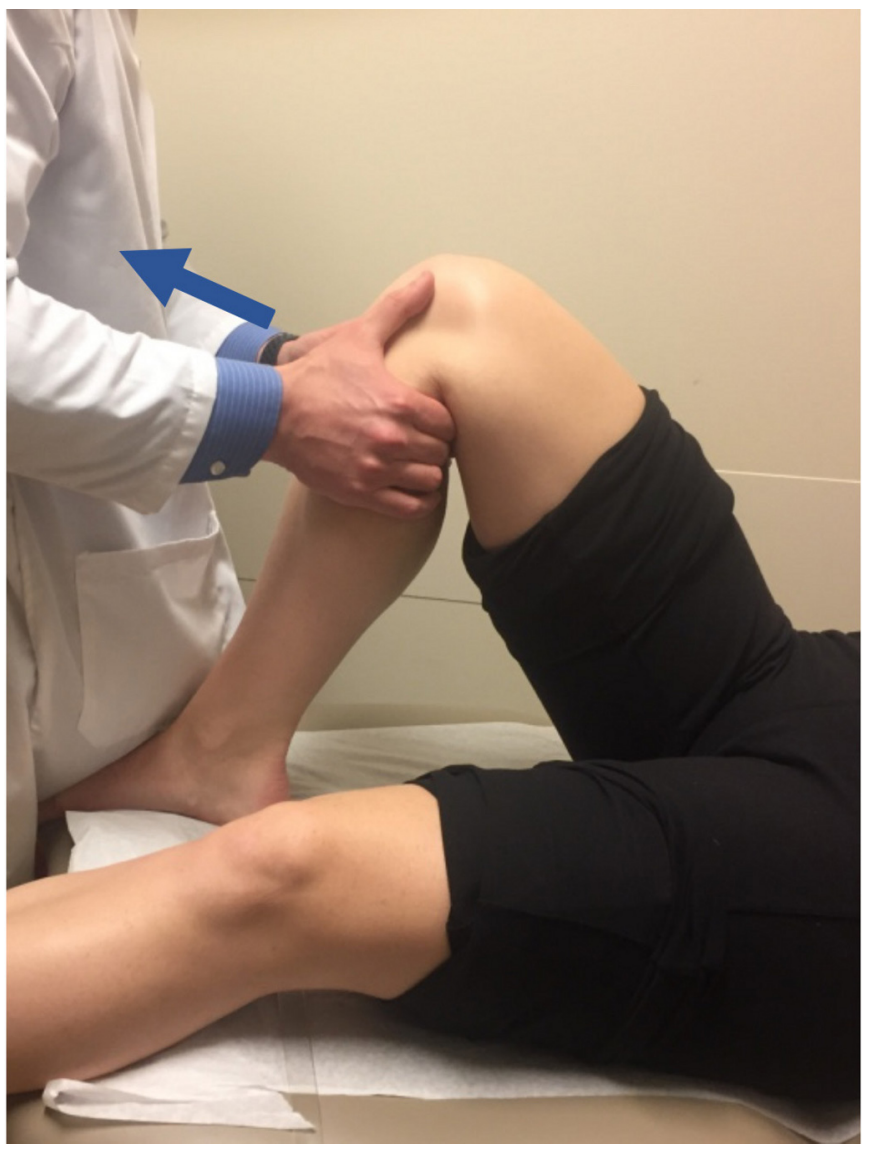

Figure 10 Anterolateral drawer test-with the patient supine and knee flexed to $90^{\circ}$, an anteriorly directed load is applied to the proximal tibia in both neutral rotation and $15^{\circ}$ external rotation. If the externally rotated knee translates over the anteromedial tibia equal to or more than the neutrally positioned knee, the test is considered positive, indicating injury to posteromedial structures. in the neutral posterior drawer test. It was initially proposed that internal tibial rotation would recruit additional capsuloligamentous structures resulting in decreased posterior motion. Ritchie $e a^{48}$ analysed this manoeuvre in a cadaveric study and concluded that the sMCL is the specific structure responsible for significantly decreasing the posterior translation when the tibia is internally rotated. They also determined that the POL, $\mathrm{dMCL}$ and meniscofemoral ligaments do not contribute to this phenomenon. Some authors have recommended assessing for posterolateral rotatory instability during internal rotation which can implicate posterolateral corner injury. ${ }^{3349}$ Lubowitz et al also described the posterior Lachman manoeuvre. ${ }^{33}$ This variant of the posterior drawer is performed with the knee flexed to $30^{\circ}$ while a posteriorly directed force is applied. Increased posterior translation of the tibia indicates PCL injury (figure 5).

\section{Dial test}

The dial test examines the integrity of the PCL and the posterolateral corner. It is typically performed by a single examiner on the patient in prone position by applying an external rotation load to bilateral feet and comparing the difference in side-toside external rotation with the knee in both $30^{\circ}$ and $90^{\circ}$ of knee flexion. An assistant may be used to maintain thigh rotation. Increased external rotation at $30^{\circ}$ implicates deficiency of the PLC. Increased external rotation at both $30^{\circ}$ and $90^{\circ}$ implicates deficiency of both the PCL and the PLC. ${ }^{5051}$ The dial test may also be performed on a patient in supine position, but two examiners are needed-one to hold the hip and knee flexed, and the other to rotate the foot/lower extremity (figure 6).

Nuances to the dial test have been well described. Jung et al evaluated the reliability of different methods of performing the dial test in patients with known PCL and posterolateral corner injuries. ${ }^{34}$ Two practitioners performed an examination at two time points before surgery. All tests were performed in the supine position with and without an anteriorly directed force on the tibia. They proposed that the anterior force would reduce the posterolaterally subluxated lateral plateau. They additionally compared measurements of the thigh-foot angle with the patella-tubercle angle and found the patella-tubercle angle to have near-perfect intra-observer and inter-observer agreement while thigh-foot angle had only substantial agreement. ${ }^{34}$ One of the most notable findings was that applying an anterior force to the tibia significantly increased the external rotation of the injured knee relative to the contralateral side by an additional $6^{\circ}$ of thigh foot angle and $4^{\circ}$ of patella-tubercle angle at both $30^{\circ}$ and $90^{\circ}$ of knee flexion. Their data suggest that an anteriorly directed tibial force should be applied while performing the dial test in supine position to fully elicit side-to-side difference. Performing this manoeuvre in prone position may eliminate the posterior tibial sag, reducing the need for an active anterior tibial force. They also favour the use of patella-tubercle angle as a more reliable reference than the thigh-foot angle to measure rotational differences between the limbs.

LaPrade and colleagues recommend performing the dial test in both supine and prone positions as the supine position allows the examiner to more easily assess anteromedial versus posterolateral subluxation. Anteromedial subluxation implies posteromedial corner injury while posterolateral subluxation implies posterolateral corner injury. ${ }^{19}$

Bae et al assessed the dial test in a cadaveric study. ${ }^{51}$ With the knee at $30^{\circ}$ of flexion and the PCL intact, the relative increase in external rotation only became significant once the LCL, PFL and PLT were all sectioned. This implies that the $30^{\circ}$ state of the 


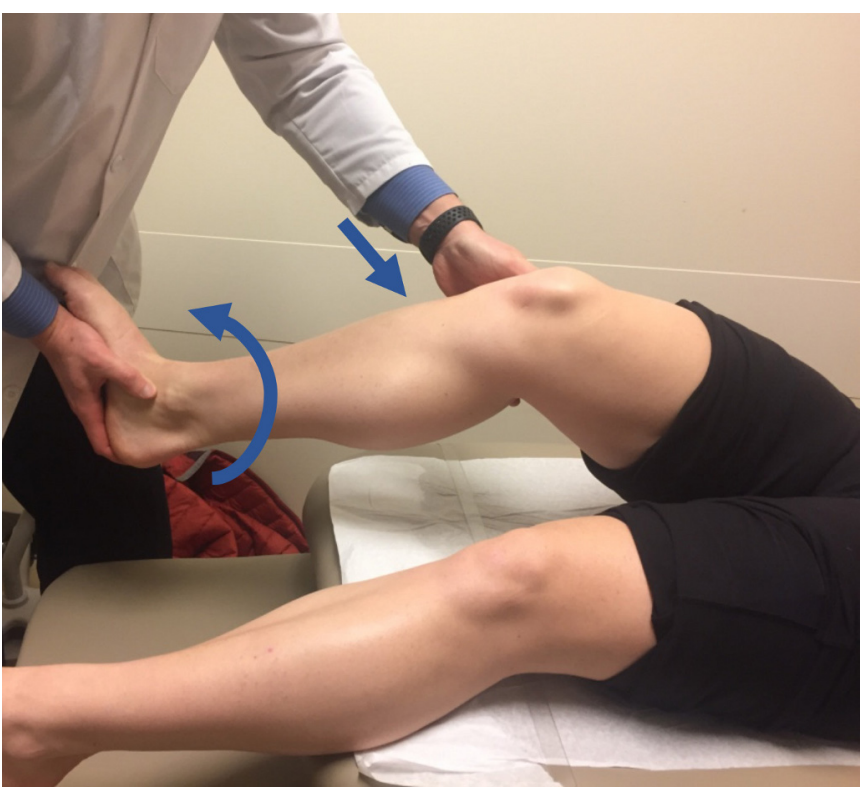

Figure 11 Anteromedial rotatory instability test—with the patient supine and knee held in $30^{\circ}$ of flexion, the examiner supports the knee with a static external rotation stress. A valgus stress is then imparted. The presences of rotatory instability, valgus gapping or anterior subluxation of the medial tibial plateau indicate injury to the medial collateral ligament and posteromedial corner.

dial test requires injury to several posterolateral structures of the knee. English and Perret also reported limitations of the dial test when used to assess partial tears of the posterolateral corner and discussed positioning of the tibia during prone and supine dial testing. ${ }^{52}$

\section{Reverse pivot shift test}

The reverse pivot shift test assesses for posterolateral rotatory instability. With the patient in supine position and the knee flexed to $90^{\circ}$, the tibia is externally rotated, and a valgus moment and axial load are applied. The knee is then gradually extended. As

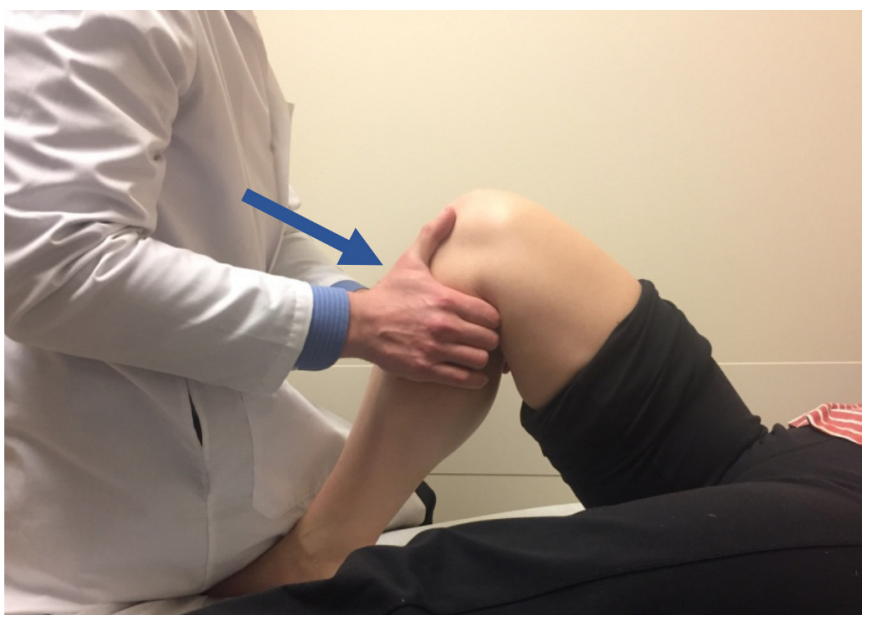

Figure 12 Posterior drawer manoeuvre - with the patient supine and knee flexed to $90^{\circ}$, the examiner stabilises the foot and places a thumb spanning the joint line. After bringing the tibia anterior to the medial femoral condyle, the examiner applies a posterior load assessing for posterior translation of the medial tibial plateau relative to the medial femoral condyle.

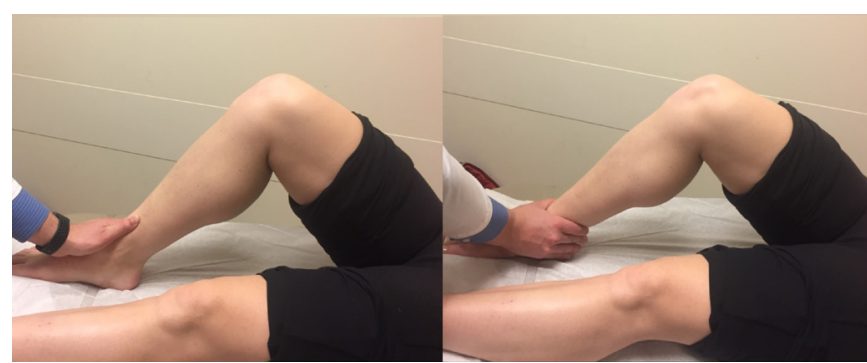

Figure 13 Posterior sag and quadriceps active tests - with the patient supine, the knee is flexed to $90^{\circ}$ with foot resting on the examination table. Left image: the posterior sag test is positive if the medial tibial plateau is posterior to the medial femoral condyle with the patient relaxed. Right image: the quadriceps active test is positive if the knee reduces when the patient contracts the quadriceps with the ankle supported. These images demonstrate a negative examination.

the iliotibial band's force vector changes from flexion to extension, a palpable reduction of the posteriorly subluxated lateral tibial condyle indicates injury to posterolateral structures. ${ }^{33}$ The reverse pivot shift has been demonstrated to have a false-positive rate of up to $30 \%$ in normal knees ${ }^{33}$ (figure 7 ).

\section{Posterolateral drawer test}

Posterolateral drawer test was described by Hughston and Norwood in 1980 as a posterior drawer test with the tibia in $15^{\circ}$ of external rotation. The examiner palpates the lateral tibial plateau to assess for posterior subluxation indicative of a PLC injury and possibly concomitant PCL injury. ${ }^{57}$ The manoeuvre has subsequently been described differently. With the patient in supine position, and the knee flexed to $90^{\circ}$, the examiner applies a posterior and external rotation force to the proximal tibia, while palpating the anteromedial tibia, assessing for anteromedial tibial step-off. ${ }^{43}$ Levy and colleagues provided an important caveat to the posterolateral drawer stating that "The take-home message of these diagnostic studies is that, although these tests are likely to be positive in patients with PLC injury, they may not be attributed to any one structure nor have their exact sensitivity nor specificity been evaluated in a population of multiligamentinjured knees" ${ }^{53}$ (figure 8).

\section{Figure-of-four manoeuvre}

Placing the injured leg in the figure-of-four by bringing the lateral ankle of the injured extremity to the anterior thigh of the uninjured side allows for direct palpation of the taut LCL. ${ }^{53}$ Absence of a palpable LCL is considered positive (figure 9).

\section{Posteromedial examination manoeuvres}

Anterolateral drawer test

Slocum and Larson, in 1968, described one of the initial tests to evaluate for anteromedial rotatory instability. ${ }^{33} 54$ The manoeuvre is a two-part variant of the anterior drawer examination designed to isolate posteromedial structures in the setting of an ACL-deficient knee. The knee is flexed to $90^{\circ}$ and an anteriorly directed force is applied with the tibia in both neutral rotation and $15^{\circ}$ external rotation (figure 10 ). The externally rotated state is designed to recruit the posteromedial structures as secondary restraints. The posteromedial structures are considered intact if the translation is less in the externally rotated position than the neutral position. Equal or increased translation suggests incompetence of the posteromedial structures. LaPrade and Wijdicks" ${ }^{19}$ suggest that, "Assessment of the amount of 


\section{Box 1 Key articles}

1. Hughston JC, Andrews JR, Cross MJ, Moschi A. Classification of knee ligament instabilities partKnee Ligament Instabilities Part II. The lateral compartmenLateral Compartment. J Bone Jt Surg. 1976;58(2):173-179.

2. Gollehon DL, Torzilli PA, Warren RF. The role of posterolateral and cruciate ligaments in the stability of the human knee: a biomechanical study. J Bone Jt Surg. 1987;69(2):233-242.

3. Mains DB, Andrews JG, Stonecipher T. Medial and anteriorposterior ligament stability of the human knee, measured with a stress apparatus. Am J Sports Med. 1977;5(4):144153. doi:10.1177/036354657700500402

4. Markolf KL, Wascher DC, Finerman GAM. Direct in Vitrovitro Measurement of Forces in the Cruciate Ligaments measurement of forces in the cruciate ligaments. Part II: the effect of section of the posterolateral structures. J Bone Jt Surg. 1993;75(3):387-394.

5. Veltri DM, Xiang-Hua Deng, Torzilli PA, Maynard MJ, Warren RF. The role of the popliteofibular ligament in stability of the human knee: a biomechanical study. Role of the Popliteofibular Ligament in Stability of the Human Knee: A Biomechanical Study. Am J Sports Med. 1996;24(1):19-27. doi:10.1177/036354659602400105

6. Ritchie, JR, Bergfeld, JA, Kambic, H, Manning, T: Isolated Sectioning of the Medial and Posteromedial Capsular Ligaments in the sectioning of the medial and posteromedial capsular ligaments in the Posterior Cruciate Ligamentposterior cruciate ligament-Deficient Knee-deficient knee. Am J Sports Med 1998;26:389-394.

7. Griffith CJ, Wijdicks CA, LaPrade RF, Armitage BM, Johansen S, Engebretsen L. Force Measurements on the measurements on the Posterior Oblique Ligamentposterior oblique ligament and and Superficial Medial Collateral Ligamentsuperficial medial collateral ligament Proximal and Distal Divisions to Applied Load proximal and distal divisions to applied loads. Am J Sports Med. 2009;37(1):140-148. doi:10.1177/0363546508322890

8. Sekiya JK, Whiddon DR, Zehms CT, Miller MD. A Clinically Relevant Assessment of clinically relevant assessment of Posterior Cruciate Ligamentposterior cruciate ligament and Posterolateral Corner Injuries: Evaluation of Isolated and Combined Deficiency. and posterolateral corner injuries: evaluation of isolated and combined deficiency. J Bone Jt Surg 2008;90(8):1621-1627. doi:10.2106/JBJS.G.01365

9. LaPrade RF, Bernhardson AS, Griffith CJ, Macalena JA, Wijdicks CA. Correlation of Valgus Stress Radiographs with Medial Knee Ligament Injuries: An valgus stress radiographs with medial knee ligament injuries: an in Vitroin vitro Biomechanical Study biomechanical study. Am J Sports Med. 2010;38(2):330-338. doi:10.1177/0363546509349347

10. Lubowitz JH, Bernardini BJ, Reid JB. Current concepts review: comprehensive physical examination for instability of the kneeConcepts Review: Comprehensive Physical Examination for Instability of the Knee. Am J Sports Med. 2008;36(3):577-594. doi:10.1177/0363546507312641

anteromedial rotation in a medial knee injury is also important to determine whether the injury primarily affects the superficial MCL or the posterior oblique ligament and deep MCL”.

Slocum and Larson also advocated performing the test with $30^{\circ}$ of internal rotation to assess the competency of posterolateral
Box 2 Validated outcome measures and classifications

- The physical examination manoeuvres most frequently used by the authors for assessment of posteromedial and posterolateral corner injury are the reverse pivot shift, the dial test, the posterior drawer, and the varus and valgus tests.

structures of the knee which should reduce anterior translation when intact. They report an important caution that if the posterolateral structures are compromised, the utility of the anterolateral drawer test for posteromedial structures is limited, a caution that has been echoed by other authors. ${ }^{18} 5455$

\section{Anteromedial rotatory instability test}

Dold et al describe an additional physical examination manoeuvre for the posteromedial corner. ${ }^{56}$ A valgus stress is applied to a knee held at $30^{\circ}$ of flexion with external rotation. The presence of rotatory instability, valgus gapping or anterior subluxation of the medial plateau indicates a positive test signalling injury to the MCL and posteromedial corner ${ }^{56}$ (figure 11).

\section{Anteromedial drawer test}

Wijdicks described the anteromedial drawer test as flexion of the knee to $90^{\circ}$, external rotation of the foot to $10^{\circ}-15^{\circ}$ and application of an anteromedial rotatory force. Tibial subluxation anteriorly indicates injury to the posterior oblique ligament and/or posteromedial capsule. This rotatory instability should be differentiated from posterolateral subluxation which occurs with posterolateral corner injury as these can appear similarly but implicate different injury patterns. ${ }^{18} 56$

\section{Valgus stress test}

The traditional valgus stress test is performed on the supine patient by applying a valgus load to the knee flexed to $30^{\circ}$ and extended to $0^{\circ}$ to assess the integrity of the MCL. The degree of medial opening is clinically assessed. LaPrade et al advocated for a radiographic valgus stress test because of its ability to objectively measure the degree of medial knee instability. ${ }^{32}$ They conclude that increased medial gapping asymmetry of greater than $3.2 \mathrm{~mm}$ with the knee held at $20^{\circ}$ of flexion implies a grade III MCL injury.

\section{Posterior instability examination manoeuvres}

Posterior drawer test

The posterior drawer assesses the integrity of the PCL. The examiner should begin with the tibial plateau $1 \mathrm{~cm}$ anterior to the medial femoral condyle with the knee flexed to $90^{\circ}$. Placing thumbs on the anteromedial and anterolateral joint line allows

\section{Box 3 Key issues of patient selection}

- In the setting of acute injury, patient guarding may limit the sensitivity of examination manoeuvres.

- Examination under anaesthesia may be considered in patients unable to tolerate awake examination.

- Examiners may consider use of intra-articular local anaesthetic injection to reduce patient guarding.

- Clinical suspicion for vascular injury must be high when evaluating multi-ligamentous knee injuries and should be appropriately assessed. 
Box 4 Typical features of diagnostic procedures

- Accurate physical examination requires a compliant patient, visual inspection and palpation of motion, and, ideally, comparison with an uninjured contralateral knee.

- Instrumented systems typically immobilise adjacent joints and apply reproducible precise loads to the knee.

\section{Box 5 Tips and tricks}

- Begin drawer manoeuvres with an initial reducing force to obtain a true neutral displacement.

- Support the patient's limb to minimise guarding.

- Compare the injured knee with the contralateral control.

- Place the thumb pad over the joint line to simultaneously palpate the tibial plateau and the femoral condyle to accurately assess for anterior-posterior translation.

- Differentiate between anteromedial rotatory instability and posterolateral rotatory instability by assessing the relative position of the tibial plateau to femoral condyles.

\section{Box 6 Major pitfalls}

- Patient guarding may lead to false negatives, especially in the acutely injured patient.

- False negatives may occur when the physician does not reduce tibial subluxation prior to performing the examination manoeuvre.

- The supine dial test requires an assistant to stabilise the knee and hip when performed.

assessment of posterior translation with posteriorly directed force. Posterior translation of 0 to $5 \mathrm{~mm}$ is consistent with Grade I instability, $5-10 \mathrm{~mm}$ with Grade II instability and $>10 \mathrm{~mm}$ with Grade III instability. ${ }^{57}$ Kowalcuk et al noted a $90 \%$ sensitivity and $99 \%$ specificity for PCL injury using the posterior drawer test. ${ }^{58}$ It is important to perform the posterior drawer manoeuvre with the tibia in neutral rotation to isolate the PCL (figure 12).

Posterior sag test and quadriceps active test

The posterior sag test is performed with the patient in supine position with knees flexed to $90^{\circ}$. The position of the tibial plateau relative to the femoral condyles is compared with the contralateral knee with muscles relaxed. The medial tibial plateau is normally $1 \mathrm{~cm}$ anterior to the medial femoral condyle. The quadriceps active test can be performed by then asking the patient to fire the quadriceps muscles while the examiner holds the ankle as described by Daniel et al. An anterior shift of the tibia greater than $2 \mathrm{~mm}$ is indicative of PCL deficiency ${ }^{59}$ (figure 13).

\section{ASSESSMENT OF ACCURACY}

Bonadio et al correlated physical examination and MRI with intraoperative finding of a variety of knee injuries. ${ }^{60}$ They found MRI had a sensitivity of $100 \%$ for ACL injuries, $87 \%$ for PCL injuries, $58 \%$ for LCL injuries, and 24\% for popliteus tendon injuries when compared with physical examination and intraoperative findings. They concluded that MRI was not as sensitive as physical examination for peripheral injuries.

Levy et al explain the importance of performing the posterolateral drawer in the setting of a positive varus stress test. A negative posterolateral drawer in the setting of varus instability indicates an isolated LCL rupture, while a positive test indicates additional injury of the posterolateral structures. ${ }^{43}$

\section{GEOGRAPHICAL DIFFERENCES}

The authors are not aware of any significant geographical differences in the understanding of posteromedial and posterolateral corner biomechanics or the application of physical examination manoeuvres because many of the recent advances in this area have been studied and reported with international consensus. MRI access may be more readily available in wealthier countries for confirmatory data, but physical examination remains a staple to accurate diagnosis. Geography does influence treatment techniques and strategies, but that is beyond the scope of this article.

\section{FUTURE PERSPECTIVES}

The posteromedial and posterolateral structures of the knee perform important primary and secondary stabilising functions. Biomechanical studies continue to elucidate the specific static contributions of discrete structures of the posteromedial and posterolateral corners and may further characterise the dynamic interplay of these structures. Surgeons have several physical examination manoeuvres at their disposal to aid in the diagnosis of injuries to these structures. When left untreated, incompetent posteromedial and posterolateral structures of the knee can compromise cruciate ligament reconstructions and can lead to chronic instability. It is important that surgeons use all tools at their disposal to properly diagnose such injuries to develop appropriate treatment plans.

Acknowledgements The authors express our gratitude to João V Novaretti and Mark E Cinque for their contributions.

Contributors STS contributed conception, design, data acquisition, analysis and interpretation of data, drafting of manuscript, acquisition of clinical images and critical revisions. RL, LE and MC contributed critical revisions of the manuscript for important intellectual content. MS contributed conception, design and critical revision of the manuscript for important intellectual content.

Funding The authors have not declared a specific grant for this research from any funding agency in the public, commercial or not-for-profit sectors.

Competing interests None declared.

Patient consent for publication Not required.

Provenance and peer review Commissioned; externally peer reviewed.

Data availability statement All data relevant to this study are included in the article.

\section{ORCID iD}

Steven T Swinford http://orcid.org/0000-0003-3208-3181

\section{REFERENCES}

1 Sekiya JK, Whiddon DR, Zehms CT, et al. A clinically relevant assessment of posterior cruciate ligament and posterolateral corner injuries. Evaluation of isolated and combined deficiency. J Bone Joint Surg Am 2008;90:1621-7.

2 O'Brien SJ, Warren RF, Pavlov H, et al. Reconstruction of the chronically insufficient anterior cruciate ligament with the central third of the patellar ligament. J Bone Joint Surg Am 1991;73:278-86

3 Cooper DE. Tests for posterolateral instability of the knee in normal subjects. Results of examination under anesthesia. J Bone Joint Surg Am 1991;73:30-6.

4 LaPrade RF, Muench C, Wentorf F, et al. The effect of injury to the posterolateral structures of the knee on force in a posterior cruciate ligament graft: a biomechanical study. Am J Sports Med 2002;30:233-8.

5 Hughston JC, Norwood Jr LA. The posterolateral drawer test and external rotational recurvatum test for posterolateral rotatory instability of the knee. Clin Orthop Rel Res 1980;147:82-7

6 Grood ES, Noyes FR, Butler DL, et al. Ligamentous and capsular restraints preventing straight medial and lateral laxity in intact human cadaver knees. J Bone Joint Surg Am 1981;63:1257-69.

7 Gollehon DL, Torzilli PA, Warren RF. The role of the posterolateral and cruciate ligaments in the stability of the human knee. A biomechanical study. J Bone Joint Surg Am 1987;69:233-42. 
8 Cinque ME, Chahla J, Kruckeberg BM, et al. Posteromedial corner knee injuries: diagnosis, management, and outcomes: a critical analysis review. JBJS Rev 2017;5:e4.

9 Chahla J, Moatshe G, Dean CS, et al. Posterolateral corner of the knee: current concepts. Arch Bone Jt Surg 2016;4:97-103.

10 Malone AA, Dowd GSE, Saifuddin A. Injuries of the posterior cruciate ligament and posterolateral corner of the knee. Injury 2006;37:485-501.

11 Lundquist RB, Matcuk GR, Schein AJ, et al. Posteromedial corner of the knee: the neglected corner. Radiographics 2015:35:1123-37.

12 Beltran J, Matityahu A, Hwang K, et al. The distal semimembranosus complex: normal MR anatomy, variants, biomechanics and pathology. Skeletal Radiol 2003;32:435-45.

13 Sims WF, Jacobson KE. The posteromedial corner of the knee: medial-sided injury patterns revisited. Am I Sports Med 2004;32:337-45.

14 Griffith CJ, Wijdicks CA, LaPrade RF, et al. Force measurements on the posterior oblique ligament and superficial medial collateral ligament proximal and distal divisions to applied loads. Am J Sports Med 2009;37:140-8.

15 Griffith CJ, LaPrade RF, Johansen S, et al. Medial knee injury: Part 1, static function of the individual components of the main medial knee structures. Am J Sports Med 2009;37:1762-70

16 Robinson JR, Bull AMJ, Thomas RRD, et al. The role of the medial collateral ligament and posteromedial capsule in controlling knee laxity. Am J Sports Med 2006:34:1815-23.

17 Wijdicks CA, Griffith CJ, LaPrade RF, et al. Medial knee injury: Part 2, load sharing between the posterior oblique ligament and superficial medial collateral ligament. Am J Sports Med 2009:37:1771-6.

18 Wijdicks CA, Griffith CJ, Johansen S, et al. Injuries to the medial collateral ligament and associated medial structures of the knee. J Bone Joint Surg Am 2010;92:1266-80

19 LaPrade RF, Wijdicks CA. The management of injuries to the medial side of the knee. Orthop Sports Phys Ther 2012;42:221-33.

20 LaPrade RF, Heikes C, Bakker AJ, et al. The reproducibility and repeatability of varus stress radiographs in the assessment of isolated fibular collateral ligament and gradeIII posterolateral knee injuries. An in vitro biomechanical study. J Bone Joint Surg Am 2008:90:2069-76.

21 Covey DC. Injuries of the posterolateral corner of the knee. J Bone Joint Surg Am 2001:83:106-18.

22 Veltri DM, Deng XH, Torzilli PA, et al. The role of the cruciate and posterolateral ligaments in stability of the knee. A biomechanical study. Am I Sports Med 1995;23:436-43.

23 Höher J, Harner CD, Vogrin TM, et al. In situ forces in the posterolateral structures of the knee under posterior tibial loading in the intact and posterior cruciate ligamentdeficient knee. J Orthop Res 1998;16:675-81.

24 LaPrade RF, Wozniczka JK, Stellmaker MP, et al. Analysis of the static function of the popliteus tendon and evaluation of an anatomic reconstruction: the "fifth ligament" of the knee. Am J Sports Med 2010;38:543-9.

25 Maynard MJ, Deng X, Wickiewicz TL, et al. The popliteofibular ligament. rediscovery of a key element in posterolateral stability. Am J Sports Med 1996;24:311-6.

26 Veltri DM, Deng XH, Torzilli PA, et al. The role of the popliteofibular ligament in stability of the human knee. A biomechanical study. Am I Sports Med 1996;24:19-27.

27 McCarthy M, Camarda L, Wijdicks CA, et al. Anatomic posterolateral knee reconstructions require a popliteofibular ligament reconstruction through a tibial tunnel. Am J Sports Med 2010;38:1674-81.

28 Mains DB, Andrews JG, Stonecipher T. Medial and anterior-posterior ligament stability of the human knee, measured with a stress apparatus. Am I Sports Med 1977:5:144-53.

29 LaPrade CM, Civitarese DM, Rasmussen MT, et al. Emerging updates on the posterior cruciate ligament: a review of the current literature. Am I Sports Med 2015;43:3077-92.

30 Markolf KL, Wascher DC, Finerman GA. Direct in vitro measurement of forces in the cruciate ligaments. Part II: the effect of section of the posterolateral structures. J Bone Joint Surg Am 1993;75:387-94.

31 Kennedy NI, Wijdicks CA, Goldsmith MT, et al. Kinematic analysis of the posterior cruciate ligament, part 1: the individual and collective function of the anterolateral and posteromedial bundles. Am J Sports Med 2013;41:2828-38.

32 LaPrade RF, Bernhardson AS, Griffith CJ, et al. Correlation of valgus stress radiographs with medial knee ligament injuries: an in vitro biomechanical study. Am I Sports Med 2010;38:330-8.

33 Lubowitz JH, Bernardini BJ, Reid JB. Current concepts review: comprehensive physical examination for instability of the knee. Am J Sports Med 2008;36:577-94.

34 Jung Y-B, Lee YS, Jung $\mathrm{H}-\mathrm{J}$, et al. Evaluation of posterolateral rotatory knee instability using the dial test according to tibial positioning. Arthroscopy 2009;25:257-61.
35 Branch TP, Stinton SK, Siebold R, et al. Assessment of knee laxity using a robotic testing device: a comparison to the manual clinical knee examination. Knee Surg Sports Traumatol Arthrosc 2017;25:2460-7.

36 Almquist PO, Arnbjörnsson A, Zätterström R, et al. Evaluation of an external device measuring knee joint rotation: an in vivo study with simultaneous roentgen stereometric analysis. J Orthop Res 2002;20:427-32.

37 Almquist PO, Ekdahl C, Isberg P-E, et al. Measurements of knee rotation-reliability of an external device in vivo. BMC Musculoskelet Disord 2011;12:291.

38 Ruiz N, Filippi GJ, Gagnière B, et al. The comparative role of the anterior cruciate ligament and anterolateral structures in controlling passive internal rotation of the knee: a biomechanical study. Arthroscopy 2016;32:1053-62.

39 Lorbach $\mathrm{O}$, Wilmes P, Maas S, et al. A non-invasive device to objectively measure tibial rotation: verification of the device. Knee Surg Sports Traumatol Arthrosc 2009;17:756-62.

40 Lorbach 0 , Wilmes $\mathrm{P}$, Theisen $\mathrm{D}$, et al. Reliability testing of a new device to measure tibial rotation. Knee Surg Sports Traumatol Arthrosc 2009;17:920-6.

41 Branch TP, Browne JE, Campbell JD, et al. Rotational laxity greater in patients with contralateral anterior cruciate ligament injury than healthy volunteers. Knee Surg Sports Traumatol Arthrosc 2010;18:1379-84.

42 Un BS, Beynnon BD, Churchill DL, et al. A new device to measure knee laxity during weightbearing and non-weightbearing conditions. J Orthop Res 2001;19:1185-91.

43 Levy BA, Boyd JL, Stuart MJ. Surgical treatment of acute and chronic anterior and posterior cruciate ligament and lateral side injuries of the knee. Sports Med Arthrosc Rev 2011;19:110-9.

44 LaPrade RF, Terry GC. Injuries to the posterolateral aspect of the knee. Association of anatomic injury patterns with clinical instability. Am I Sports Med 1997;25:433-8.

45 Hughston JC, Jacobson KE. Chronic posterolateral rotatory instability of the knee. J Bone Joint Surg Am 1985;67:351-9.

46 LaPrade RF, Ly TV, Griffith C. The external rotation recurvatum test revisited: reevaluation of the sagittal plane tibiofemoral relationship. Am I Sports Med 2008;36:709-12.

47 Cinque ME, Geeslin AG, Chahla J, et al. The heel height test: a novel tool for the detection of combined anterior cruciate ligament and fibular collateral ligament tears. Arthroscopy 2017;33:2177-81.

48 Ritchie JR, Bergfeld JA, Kambic H, et al. Isolated sectioning of the medial and posteromedial capsular ligaments in the posterior cruciate ligament-deficient knee. Influence on posterior tibial translation. Am J Sports Med 1998;26:389-94.

49 Hughston JC, Andrews JR, Cross MJ, et al. Classification of knee ligament instabilities. Part II. The lateral compartment. J Bone Joint Surg Am 1976;58:173-9.

50 Loomer RL. A test for knee posterolateral rotatory instability. Clin Orthop Relat Res 1991;264:235-8

51 Bae JH, Choi IC, Suh SW, et al. Evaluation of the reliability of the dial test for posterolateral rotatory instability: a cadaveric study using an isotonic rotation machine. Arthroscopy 2008;24:593-8.

52 English S, Perret D. Posterior knee pain. Curr Rev Musculoskelet Med 2010;3:3-10.

53 Levy BA, Stuart MJ, Whelan DB. Posterolateral instability of the knee: evaluation, treatment, results. Sports Med Arthrosc Rev 2010;18:254-62.

54 Slocum DB, Larson RL. Rotatory instability of the knee. its pathogenesis and a clinical test to demonstrate its presence. J Bone Jt Surg Am 1968;50:211-25.

55 Skendzel JG, Sekiya JK, Wojtys EM. Diagnosis and management of the multiligamentinjured knee. J Orthop Sports Phys Ther 2012;42:234-42.

56 Dold AP, Swensen S, Strauss E, et al. The posteromedial corner of the knee: anatomy, pathology, and management strategies. J Am Acad Orthop Surg 2017;25:752-61.

57 American Medical Association Committee on the medical aspects of sports, Subcommittee on classification of sports injuries. Standard nomenclature of athletic injuries. Chicago: American Medical Association, 1966.

58 Kowalczuk M, Leblanc M-C, Rothrauff BB, et al. Posterior tibial translation resulting from the posterior drawer manoeuvre in cadaveric knee specimens: a systematic review. Knee Surg Sports Traumatol Arthrosc 2015;23:2974-82.

59 Daniel DM, Stone ML, Barnett P, et al. Use of the quadriceps active test to diagnose posterior cruciate-ligament disruption and measure posterior laxity of the knee. J Bone Joint Surg Am 1988;70:386-91.

60 Bonadio MB, Helito CP, Gury LA, et al. Correlation between magnetic resonance imaging and physical exam in assessment of injuries to posterolateral corner of the knee. Acta Ortop Bras 2014;22:124-6.

61 LaPrade RF, Engebretsen AH, Ly TV, et al. The anatomy of the medial part of the knee. J Bone Joint Surg Am 2007;89:2000-10.

62 LaPrade RF, Ly TV, Wentorf FA, et al. The posterolateral attachments of the knee: a qualitative and quantitative morphologic analysis of the fibular collateral ligament, popliteus tendon, popliteofibular ligament, and lateral gastrocnemius tendon. Am J Sports Med 2003;31:854-60. 